"NÃO PENSE

\title{
EM CRISE, TRABALHE”: O JOGO DA HISTÓRIA NA TRAMA DA LÍNGUA
}

\author{
"NO PIENSE EN CRISIS, TRABAJE": \\ EL JUEGO DE LA HISTORIA EN LA TRAMA DE LA LENGUA
}

“DON’T THINK ABOUT THE CRISIS, WORK”: THE ROLE OF HISTORY IN THE PLOT OF

LANGUAGE

Dantielli Assumpção Garcia*

Universidade Estadual do Oeste do Paraná

Lucília Maria Abrahão e Sousa**

Universidade de São Paulo

\begin{abstract}
RESUMO: Neste trabalho, da perspectiva teórica da Análise de Discurso de linha francesa, mobilizando as noções de efeito metafórico (PÊCHEUX, 1997 [1969]) e de modalidade de identificação (PÊCHEUX, 2009 [1988]), analisaremos o pronunciamento do presidente interino Michel Temer, proferido na posse dos novos ministros ao governo provisório em virtude do afastamento da presidenta Dilma Rousseff, e os deslocamentos do enunciado "Não pense em crise, trabalhe", dito por Michel Temer, que circularam em diferentes postagens nas redes sociais. Mostraremos como o efeito metafórico funciona nessas postagens, produzindo furos na suposta legitimidade presidencial, uma contraidentificação dos sujeitos ao discurso que os interpela, criando, assim, espaços de resistência a um discurso de dominação e segregação dos sujeitos
\end{abstract}

PALAVRAS-CHAVE: Michel Temer. Modalidade de identificação. Efeito metafórico. Crise. Trabalho.

RESUMEN: En este trabajo, desde la perspectiva teórica del análisis del discurso de línea francesa, movilizando las nociones de efecto metafórico (PÊCHEUX, 1997 [1969]) y de modalidad de identificación (PÊCHEUX, 2009 [1988]), analizaremos el discurso del presidente interino Michel Temer, pronunciado durante la ceremonia de investidura de los nuevos ministros del gobierno provisional en virtud de la separación de la presidenta Dilma Rousseff, y los desplazamientos del enunciado "No piense en crisis, trabaje", dicho por Michel Temer, que circularon en diferentes mensajes de las redes sociales. Enseñaremos cómo el efecto

\footnotetext{
* Pós-Doutora pela Faculdade de Filosofia, Ciências e Letras de Ribeirão Preto (FFCLRP/USP). Doutora em Estudos Linguísticos pela Universidade Estadual Paulista Júlio de Mesquita Filho (UNESP). Pós-Doutora pela Universidade Estadualdo Oestedo Paraná (PNPD/CAPES). PesquisadoradoE-L@DIS - Laboratóriodiscursivo, sujeitose sentidos em movimento (FAPESP). Docente na Graduação e na Pós-Graduação em Letras da Universidade Estadual do Oeste do Paraná. E-mail:dantielligarcia@gmail.com

** Livre-Docente em Ciências da Informação e da Documentação. Professora do Curso de Graduação em Ciências da Informaça e da Documentaça e do Programa de Pós-Graduaça em Psicologia, ambos da FFCLRP/USP. Professora colaboradoradoProgramadePós-Graduaçãoem Ciência, Tecnologia e SociedadedaUfSCAR. CoordenadoradoE-L@DIS - Laboratóriodiscursivo, sujeitosesentidosem movimento (FAPESP). E-mail: luciliamasousa@gmail.com.
} 
metafórico funciona en esos mensajes, afectando la presunta legitimidad presidencial, una contraidentificación de los sujetos al discurso que los interpela, creando, así, espacios de resistencia a un discurso de dominación y segregación de los sujetos.

PALABRAS CLAVE: Michel Temer. Modalidad de identificación. Efecto metafórico. Crisis. Trabajo.

ABSTRACT: In this work, based on the theoretical perspective of French Discourse Analysis and mobilizing notions such as metaphorical effect (PÊCHEUX, 1997 [1969]) and identification modality (PÊCHEUX, 2009 [1988]), we analyze the speech of the interim president Michel Temer, given the swearing-in of new ministers due to the dismissal of president Dilma Rousseff. We also examine the displacements of the enunciation “Don't think about the crisis, work," uttered by Michel Temer, which circulated in different posts. We present how the metaphoric effect works in such posts, producing inconsistencies in the supposed presidential legitimacy, a counter-identification of the subjects with the discourse addressed to them, thus creating spaces of resistance to a discourse of domination and segregation of the subjects.

KEYWORDS: Michel Temer. Identification modality. Metaphoric effect. Crisis. Work.

\begin{abstract}
"Nesse aspecto, ele [Foucault] sem dúvida tinha razão em afirmar que talvez o século viesse a ser deleuziano um dia, porque talvez um dia o século viesse a se parecer com o pesadelo imaginado por Deleuze: o estabelecimento de um fascismo ordinário, não o fascismo histórico de Mussolini e Hitler o qual tão bem soubera mobilizar o desejo das massas - mas antes e acima de tudo 'o fascismo que está em todos nós, que assombra nossos espíritos e condutas diárias, o fascismo que nos faz amar o poder, desejar essa coisa mesma que nos domina e nos explora' ". (Elisabeth Roudinesco, Filósofos na Tormenta, 2007).
\end{abstract}

\title{
1 O DIZER E O QUANTO DELE SE FAZ TROÇA NA LÍNGUA
}

Neste texto, da perspectiva teórica da Análise de Discurso de linha francesa, trabalharemos com algumas sequências do pronunciamento de Michel Temer dirigido à nação brasileira no momento em que anuncia, de sua posição de presidente interino em virtude do afastamento da presidenta Dilma Rousseff por causa do processo de impeachment em 2016, a posse dos novos ministros no Palácio do Planalto. O discurso ${ }^{1}$ de Temer, por meio do enunciado "Não pense em crise, trabalhe", interpela os sujeitos (cidadãos brasileiros), mas esses se contraidentificam e produzem outros dizeres que passam a circular nas redes sociais. Indagamos: quais os efeitos estão em jogo quando um enunciado assim irrompe no primeiro depoimento do representante do Executivo em um conturbado momento da vida política nacional? O que representa a circulação de um imperativo que abole a reflexão sobre tal momento? Como se constrói um imaginário sobre o trabalho que dispensa do humano o que lhe é próprio, pensar? O que da boca de sujeito na posição de presidente inscreve-se como crise e saída para ela? De que trabalho estamos falando afinal e o quanto tudo isso silencia outros sentidos sobre o político?

Inferimos que na produção, circulação e reformulação desse enunciado oficial, o efeito metafórico funciona, o humor cava seus furos na sua suposta legitimidade e o poético produz efeitos inesperados em jogo, promovendo substituições que não cessam de se desdobrar. Diante desses enunciados que passam a circular no ciberespaço, colocamos aqui o nosso desejo de produzir também uma compreensão sobre esse momento histórico da sociedade brasileira, atravessando a cortina de fumaça das relações de poder, em cuja tessitura o jogo da história se enlaça com a língua. Assim, neste trabalho, nossos objetivos são: discutir teórica e analiticamente as modalidades discursivas de funcionamento subjetivo, elaboradas por Michel Pêcheux ([1988] 2009), além da noção de efeito metafórico, que sustentam o pronunciamento de Temer e as postagens dele nascidas e deslizadas.

\footnotetext{
${ }^{1}$ Quando utilizarmos a estrutura "discurso de Michel Temer", estamos compreendendo discurso não tomado como no campo da política enquanto pronunciamento, mas discursivamente, enquanto efeito de sentidos entre interlocutores, em que, no funcionamento da linguagem, se coloca em relação sujeitos e sentidos afetados pela língua e pela história. Ao dirigir-se à Nação, o presidente interino coloca-se em uma relação com os cidadãos brasileiros e faz ranger o motor da história que atualiza sentidos sobre governar, sobre o processo de impeachment, sobre crise, sobre trabalho. Nessa relação presidente interino-cidadãos, efeitos de sentidos outros surgem e ecoam na sociedade brasileira. São esses efeitos que intentamos flagrar neste texto ao analisarmos o discurso de Michel Temer na posse de seus ministros.
} 


\section{SUJEITO, METÁFORA E MODALIDADES DE IDENTIFICAÇÃO NO DISCURSO}

Toda prática discursiva, como adverte Pêcheux (2009 [1988], p. 197), está inscrita no “[...] complexo contraditório-desigualsobredeterminado" das formações discursivas que caracteriza a instância ideológica em condições históricas dadas; isso significa dizer que as formações discursivas mantêm entre si "relações de determinação dissimétricas", constituindo-se como o "[...] lugar de trabalho de reconfiguração que constitui, segundo o caso, um trabalho de recobrimento-reprodução-reinscrição ou um trabalho politicamente e/ou cientificamente produtivo" (PÊCHEUX, 2009 [1988], p. 197, grifos do autor). A prática discursiva faz funcionar o efeito do complexo das formações discursivas na forma-sujeito, uma vez que não existe prática sem sujeito. Contudo, segundo Pêcheux (2009 [1988], p. 198), não se trata de dizer que uma prática discursiva seja “[...] a prática de sujeitos (no sentido dos atos, ações, atividades de um sujeito)", mas sim de constatar que todo sujeito é constitutivamente "[...] colocado como autor de e responsável por seus atos (por suas 'condutas' e por suas 'palavras') em cada prática em que se inscreve; e isso pela determinação do complexo das formações ideológicas (e, em particular, das formações discursivas) no qual ele é interpelado em 'sujeito responsável’” (PÊCHEUX, 2009 [1988], p. 198).

A ideologia interpela o indivíduo em sujeito de seu discurso, submetendo-o à língua, significando e significando-se pelo simbólico na história. Como colocam Pêcheux e Fuchs (1997 [1969] p. 162),

O funcionamento da Ideologia em geral como interpelação dos indivíduos em sujeito (e, especificamente, em sujeitos de seu discurso) se realiza através do complexo das formações ideológicas (e especificamente, através do interdiscurso intricado nesse complexo) e fornece "a cada sujeito" sua "realidade", enquanto sistemas de evidências e significações percebidas - aceitas - experimentadas.

O paradoxo pelo qual o sujeito é chamado à existência forma-se em torno da interpretação de que "[...] a Ideologia interpela os indivíduos em sujeito" (ALTHUSSER, 1985 [1970]) que tem sempre "[...] um efeito retroativo que faz com que o indivíduo seja sempre-já-sujeito”, pois “[...] o sujeito é desde sempre um indivíduo interpelado em sujeito” (PÊCHEUX, 1997 [1969], p. 141). A interpelação ocorre de "[...] tal modo que cada um seja conduzido, sem se dar conta, e tendo a impressão de estar exercendo sua livre vontade, a ocupar o seu lugar em uma ou outra das duas classes sociais antagonistas do modo de produção (ou naquela categoria, camada ou fração de classe ligada a uma delas." (PÊCHEUX; FUCHS, 1997 [1969], p. 166).

Pêcheux (2009, p. 198-199), retomando um estudo de Paul Henry, ressalta que a interpelação supõe necessariamente:

[...] um desdobramento, constitutivo do sujeito do discurso, de forma que um dos termos representa o "locutor", ou aquele a que se habituou chamar o "sujeito da enunciação", na medida em que lhe é "atribuído o encargo pelos conteúdos colocados - portanto, o sujeito que "toma posição", com total conhecimento de causa, total responsabilidade, total liberdade etc. - e o outro termo representa "o chamado sujeito universal, sujeito da ciência ou do que se pretende como tal” (PÊCHEUX, 2009 [1988], p. 198, grifos do autor).

Discutindo a relação do sujeito da enunciação com o sujeito universal, de forma a articular as "tomadas de posição" do sujeito no processo de assujeitamento, Pêcheux (2009 [1988]) apresenta três modalidades de funcionamento subjetivo. A primeira modalidade consiste em uma superposição (um recobrimento) entre o sujeito da enunciação e o sujeito universal, de modo que a:

[...] "tomada de posição" do sujeito realiza seu assujeitamento sob a forma do "livremente consentido": essa superposição caracteriza o discurso do "bom sujeito" que reflete espontaneamente o Sujeito (em outros termos: o interdiscurso determina a formação discursiva com a qual o sujeito, em seu discurso, se identifica, sendo que o sujeito sofre cegamente essa determinação, isto é, ele realiza seus efeitos "em plena liberdade") (PÊCHEUX, 2009 [1988], p. 199, grifos do autor).

Já a segunda modalidade caracteriza o discurso do "mau sujeito", discurso no qual o sujeito da enunciação "se volta" contra o sujeito universal por meio de uma "tomada de posição" que consiste, dessa vez, 
[...] em uma separação (distanciamento, dúvida, questionamento, contestação, revolta...) com respeito ao que o "sujeito universal" lhe "dá a pensar": luta contra a evidência afetada pela negação, revertida a seu próprio terreno [...] Em suma, o sujeito, o "mau sujeito", se contra-identifica com a formação discursiva que lhe é imposta pelo "interdiscurso" como determinação exterior de sua interioridade subjetiva, o que produz as formas filosóficas e políticas do discurso-contra (isto é, contradiscurso), que constitui o ponto central do humanismo (antinatureza, contranatureza etc.) sob suas diversas formas teóricas e políticas, reformistas e esquerdista. (PÊCHEUX, 2009 [1988], p. 199-200, grifos do autor).

Por fim, a terceira modalidade subjetiva e discursiva, que toma forma de uma desidentificação, ou seja, de uma "tomada de posição não subjetiva" que inclui "[...] um trabalho (transformação-deslocamento) da forma-sujeito e não sua pura e simples anulação" (PÊCHEUX, 2009 [1988], p. 202, grifos do autor). A terceira modalidade se diferencia das duas anteriores na medida em que as modalidades de identificação e contraidentificação são reguladas pela identificação à formação discursiva dominante, a qual regula a evidência do sentido, ainda que a "tomada de posição" seja de aceitação ou de rejeição. É importante destacar que, para pensar as voltas do sujeito no discurso, o teórico da AD francesa estabelece as formas de o sujeito jogar e se relacionar com o dizer do outro já inscrito na história e com a oficialidade dos dizeres considerados compactos e oficiais. A cada movimento de identificação, são estabelecidas palavras de aliança (sempre deslocada) com e a partir da FD dominante; a cada gesto de ruptura e de recusa dos efeitos tidos como legitimados, o sujeito ocupa a brecha (constante em todo dizer) de se separar, desidentificar-se, fazer um corte nos efeitos em curso e produzir aí um outro modo de significar-se. Para refletirmos sobre essa movência nas modalidades subjetivas e discursivas, analisaremos a seguir o discurso do presidente interino do Brasil. No dia 12 de maio de 2016, Michel Temer nomeia novos ministros para seu governo provisório e profere o seguinte pronunciamento:

Nós não podemos mais falar em crise. Trabalharemos. Aliás, há pouco tempo, eu passava por um posto de gasolina na Castelo Branco e o sujeito botou uma placa lá. "Não fale em crise, trabalhe". Eu quero ver até se eu consigo espalhar essa frase em 10, 20 milhões de outdoors por todo o Brasil, porque isso cria também um clima de harmonia, de interesse, de... de... otimismo, não é verdade? Então... não vamos falar em crise, vamos trabalhar. O novo lema, não é um lema de hoje. Nosso lema é ordem e progresso. (TVUOL, 2016)

Destacamos o uso do "nós" como marca de um funcionamento do imperativo, que opera a estranha ordenança de uma palavra de ordem para o momento, palavra essa que seria válida, necessária e única para todos igualmente. Pela pesquisa de Zoppi-Fontana (1997), sabemos o quanto o "nós" inscreve um efeito imaginário, bastante efetivo diga-se de passagem, de construir uma coletividade, melhor dizendo, um efeito de simetria e inclusão de todos sob a guarda de uma mesma unidade. Cria-se, pelo efeito ideológico de evidência, um imaginário aniquilamento das diferenças e uma pretensa equivalência de posições, cuja operação silenciaria qualquer desigualdade, discordância ou contradição entre os sujeitos. No caso, o dispositivo do "nós" tranquiliza as disparidades. Da posição de presidente interino, enuncia-se o que pode e não pode ser dito: "nós não podemos mais falar em crise"; assim, temos o jogo das cisões sustentadas pela história produzindo seus efeitos na língua. Se não podemos mais, é porque já falamos muito, o que produz a equação de que a entrada do vice ao cargo de maior mandatário da nação inscreve-se como calamento da crise, como desfecho da crise, como resolução mágica das tensões da crise, como fim da crise. Há, de certo modo, uma imputação de responsabilidade de sair da crise ao cidadão, já que, como proposta governamental, o não falar em crise e o trabalho do cidadão contribuiriam para a criação de uma outra situação política/econômica (?) no Brasil. Nessa sequência discursiva, Temer aponta a autoria desse enunciado e instala um argumento de autoridade advindo do cotidiano, da sabedoria popular e dos dizeres que circulam na ordem da vida: uma placa (Imagem 1) de um posto de gasolina na Castelo Branco. 


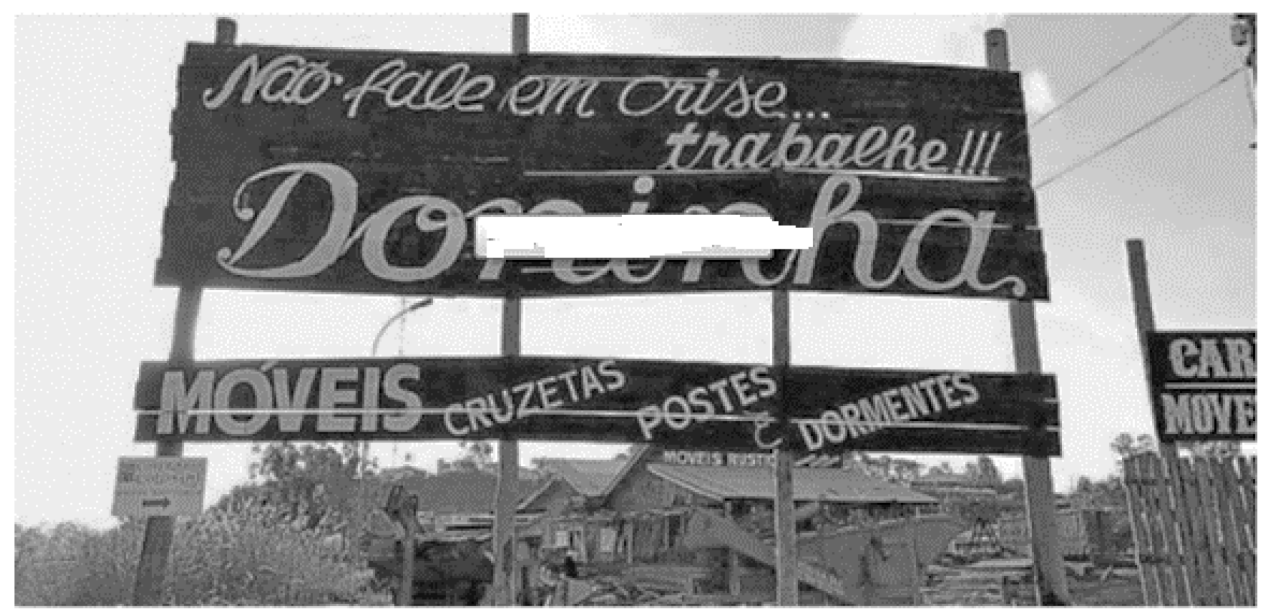

Imagem 1: Placa do posto de gasolina

Fonte: Tomazela (2016)

Esse posto de gasolina foi lacrado em 2011 por vender combustíveis adulterados e seu dono está preso por tentativa de homicídio, além de ter respondido a processo por receptação e venda de combustível roubado (TOMAZELA, 2016). Ao trazer como memória a frase colocada no posto, a fala de Temer também faz com que circule esse discurso da criminalidade e o sentido de trabalhar passa a funcionar ligado a um dizer sobre roubo, adulteração, assassinato. Seria esse o trabalho para sair da crise? Seria esse o trabalho do cidadão? Ou dos representantes da nação, uma vez que uma parte dos ministros nomeados está envolvida com a operação Lava Jato e outros tantos são acusados de diferentes crimes? Observamos aqui como o deslizamento de sentidos opera o imprevisível na ordem da língua, efeitos que nunca são mensurados ou controlados pelo sujeito. No recorte acima, a letra manuscrita faz falar o efeito de um recado marcado por reticências (não fale da crise, fale de crimes?) e por um nome próprio "Doninha" (um diminutivo feminino?), cujo endereçamento é dado aos que passam pelo local (os que andam pela estrada afora?). A precariedade da placa marca condições de produção bastante circunstanciadas, um posto de gasolina que não tem aparência de modernidade, e que foge à regra das grandes cadeias (inter)nacionais e às leis de controle de qualidade do que é vendido. Ao tomar tal dizer como argumento de citação, o sujeito-presidente o desloca, silencia as condições materiais onde circulou e o faz deslizar para outro campo.

"Eu quero ver até se eu consigo espalhar essa frase em 10, 20 milhões de outdoors por todo o Brasil", em depoimento oficial, faz deslocar o dizer da placa de estrada para outra esfera de circulação, na qual as palavras já ditas rodopiam em uma roda viva de outros efeitos agora endereçados a todos os brasileiros. Afinal são "milhões de outdoors por todo país", o que implica a mobilização do dispositivo publicitário para colocar no espaço público tal enunciado, empreitada que o sujeito-presidente considera necessária espalhar. Vejamos a fotografia abaixo, que encerra uma justaposição de duas cenas, a do chão da vida e a do dizer impresso no outdoor.

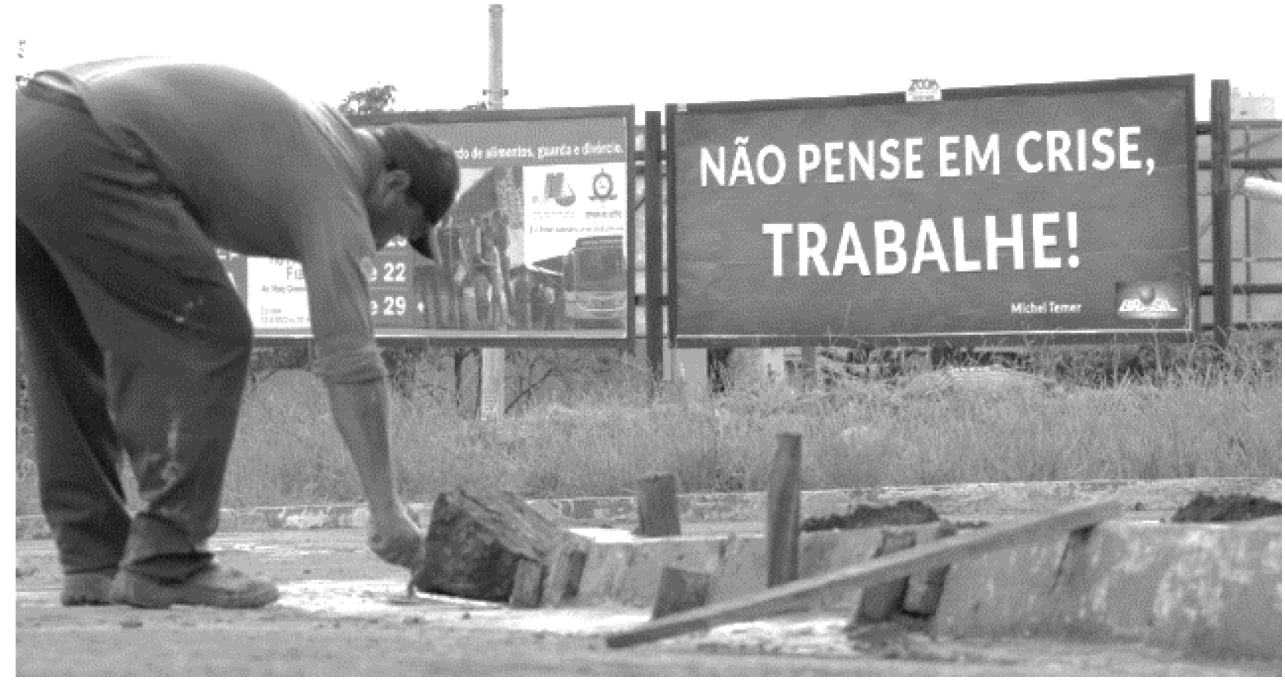

Imagem 2: Não pense em crise, trabalhe!

Fonte: Miatelo (2016) 
Indagamos: estaria o trabalho desvinculado da reflexão e do ato de pensar, também e inclusive sobre crise? Como se combinam em contradição o efeito de uma negativa e depois de uma ordem exclamativa? Não pensar seria o mesmo que eliminar? Inferimos que o sujeito-presidente instala uma restrição ordenativa - não pensar "em crise" -, o que corresponde a silenciar sobre ela e, no limite, eliminá-la do pensamento e da linguagem. É curioso que isso corresponderia ainda a apagar toda a conjuntura econômica e política a partir da qual o próprio presidente chegou ao poder, os acordos necessários com parlamentares, as discordâncias em relação à presidenta Dilma e o preço pago das alianças políticas. Crise nos remete de imediato ao econômico, sentido literal e mais recorrente nos discursos oficiais, no entanto, crise aqui se abre e desdobra-se polissemicamente em crise política, crise ética, crise de identidade, crise internacional. Ao invés de tomá-las em pensamento (e em ações políticas de mobilização e resistência, eis um dos medos), o ideal é trabalhar. A ordem é "trabalhe".

É curioso que tal assertiva comparece nesse discurso em um momento no qual o desemprego arreganha seus dentes de chumbo, cresce e ameaça trabalhadores, o que marca um modo de o sujeito-presidente também silenciar tais efeitos. É como se dissesse: emprego há, o trabalhador que faça sua parte de arregaçar as mangas e colocar-se em prontidão para o exercício das tarefas. A imagem do trabalhador braçal, assentando cimento no chão, estabelece uma relação de ressonância com o imperativo em jogo. A primeira modalidade de funcionamento subjetivo, como mostramos, tratar-se-ia do sujeito que adere à ideologia dominante explicitada no discurso de Michel Temer. Essa aderência à ideologia dominante seria análoga à submissão do sujeito ao Sujeito, isto é, na primeira modalidade, o "bom sujeito" se identifica com a formação discursiva à qual se encontra assujeitado. Teríamos aqui o sujeito que se identifica com a formulação "Não pense em crise, trabalhe".

Nas postagens que circularam nas redes sociais, o sujeito, interpelado pelo discurso de Michel Temer, não adere e nem se identifica com os sentidos que o enunciado ecoa/evoca. O sujeito, ou melhor, o "mau sujeito", pelo funcionamento subjetivo da segunda modalidade, revolta-se, questiona, contesta as evidências ideológicas da formação discursiva à qual ele se encontra assujeitado. É a partir dessa contraidentificação que o "mau sujeito" passará a produzir outros enunciados, torcendo os efeitos de trabalho para outros campos semânticos - "Não pense em crise, lute contra o golpe", "Não pense em crise, me beije” -, que, pelo funcionamento metafórico, fazem ranger e furar os sentidos produzidos pela ideologia dominante.

Já a terceira modalidade subjetiva funcionaria não como um recuo frente às evidências da ideologia dominante, mas como um modo de desidentificar-se dessas evidências com base em uma integração de conhecimentos objetivos e práticas políticas transformadoras. Como ressalta Zandwais (2003, paginação irregular), Pêcheux, indo contra a concepção de que a prática de desidentificação corresponderia à anulação da forma-sujeito, isto é, a anulação de uma formação ideológica, e, no limite, o prenúncio do fim das ideologias,

Caracteriza o processo de desidentificação, ancorado no próprio campo da prática política, como um trabalho de desarranjo-rearranjo da forma-sujeito, onde a ideologia, em uma perspectiva metafórica funciona contra e sobre si mesma, para dar sustentação a uma prática nova, em virtude de os saberes que compreende uma determinada forma-sujeito não respondem mais à necessidade de constituição dos interesses, dos objetivos antagônicos que permeiam o modo de produção/reprodução/transformação das relações de produção.

Retomando o processo de resistência-revolta-revolução discorrido por Pêcheux no texto "Só há causa daquilo que falha ou o inverno político francês: início de uma retificação”, Beck e Esteves (2012, p. 152) questionam:

Não estaria cada um destes "momentos" do processo associado as três modalidades respectivamente? Ou seja, o bom sujeito mantém-se identificado ao Sujeito, mas também resiste a Ele; o mau sujeito se contra-identifica ao Sujeito e, por isso mesmo, se revolta contra Ele, e o feio sujeito se desidentificaria e, por conseguinte, teria condições de subverter suas coordenadas ideológicas, de revolucionar as relações de força.

Nas postagens, é possível observar o funcionamento subjetivo da primeira e da segunda modalidades. Não há nas postagens uma desidentificação, uma vez que não há uma subversão das coordenadas ideológicas, mas sim a retomada do discurso/ideologia dominante para fazer frente a eles para produzir movimentos de resistência e revolta. A revolução ainda não ocorre, pois não há 
ruptura/extinção das relações de força entre as classes antagônicas (classe dominante x classe dominada; patrões x operários; presidente interino x cidadãos); tais efeitos de resistência e revolta inscrevem-se no discurso por um processo metafórico, em que a substituição de uma palavra por outra produz a emergência de dizeres contraidentificados com o discurso de Michel Temer. Em síntese, a substituição de uma palavra por outra coloca em erupção o inesperado imbricamento da história na trama da língua.

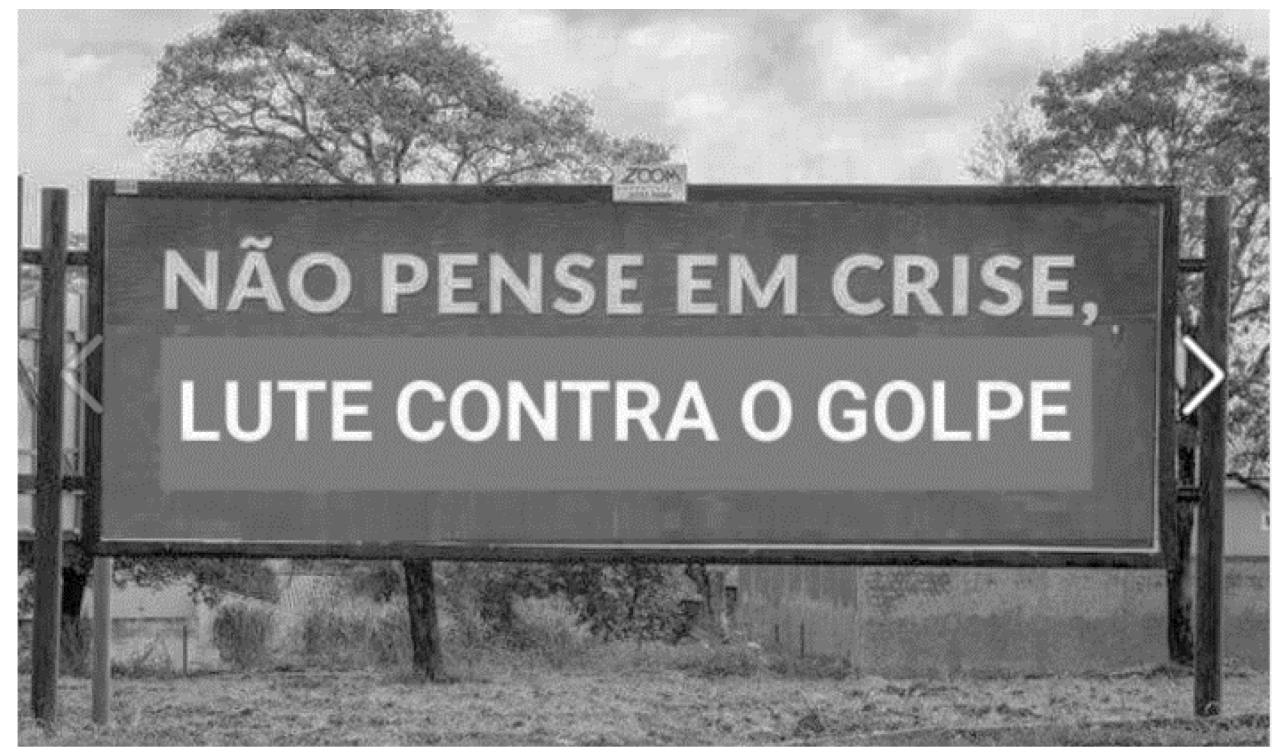

Imagem 3: Não pense em crise, lute contra o golpe

Fonte: Oliveira (2016)

\section{Pronto, arrumei para vocês.}

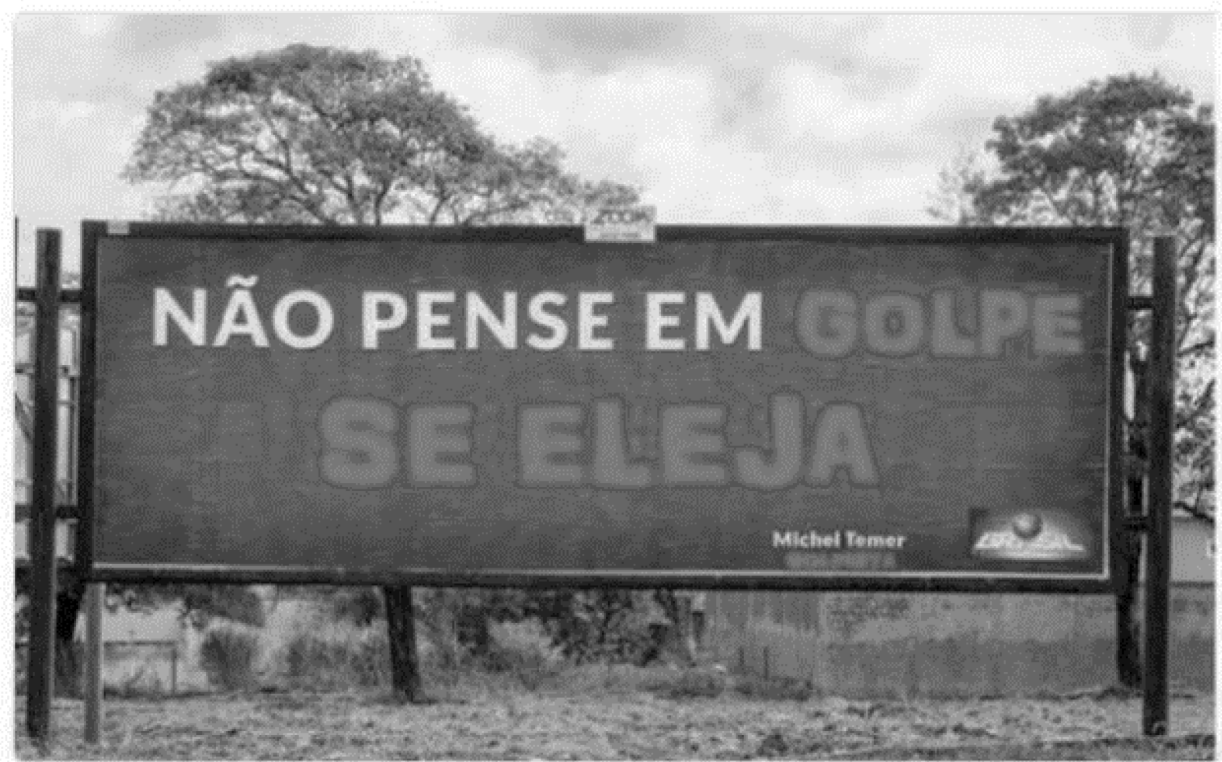

Imagem 4: Não pense em golpe se eleja

Fonte: Manotelli (2016) 


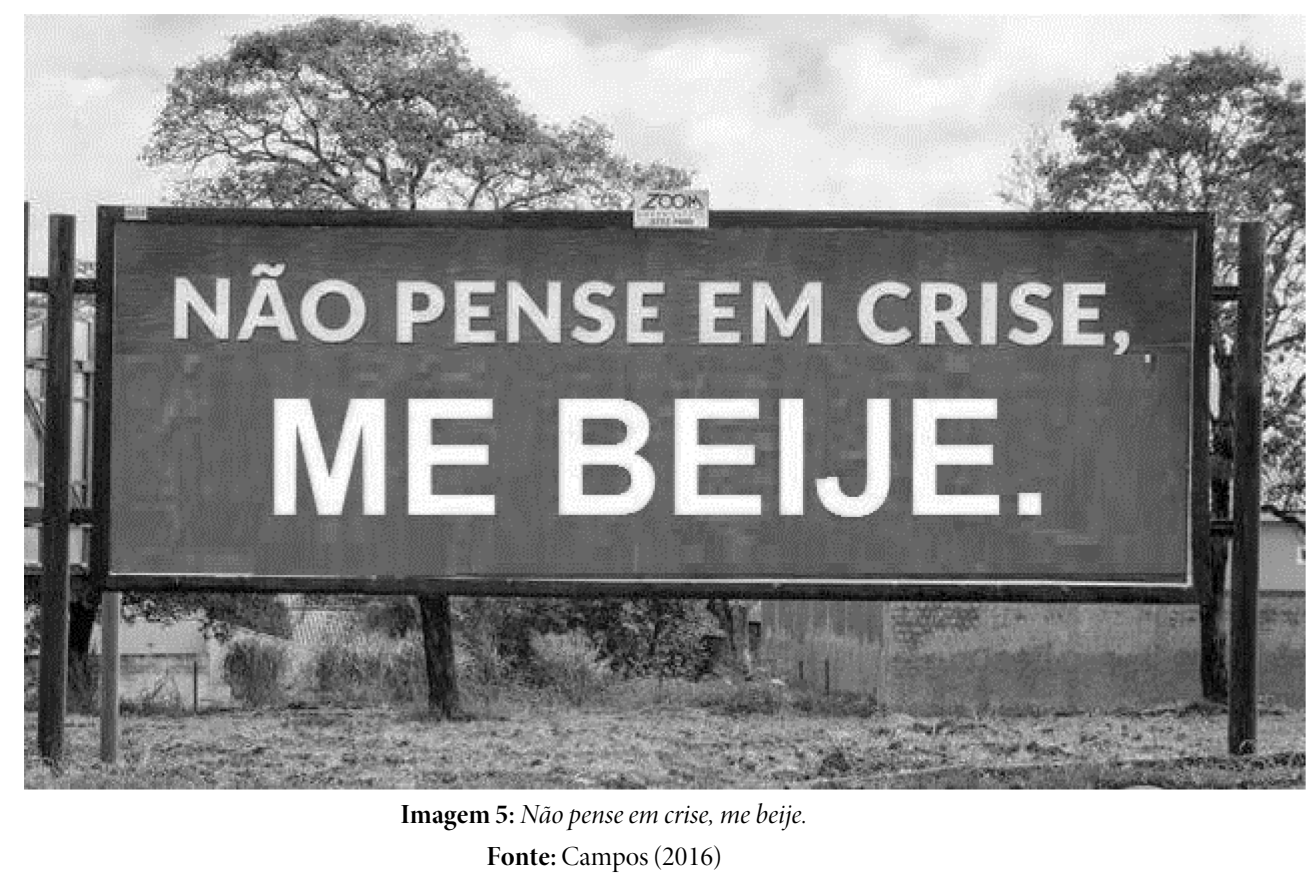

Pêcheux (1997 [1969], p. 96) define o efeito metafórico como: "[...] o fenômeno semântico produzido por uma substituição contextual para lembrar que esse deslizamento de sentido entre $x$ e $y$ é constitutivo do 'sentido' designado por $x$ e $y$; esse efeito é característico dos sistemas linguísticos naturais, por oposição aos códigos e às línguas artificiais, em que o sentido é fixado de antemão".

$\mathrm{Na}$ Análise de Discurso francesa, a metáfora, vista como uma transferência, funcionando no deslizamento entre formações discursivas, é constitutiva do processo de constituição dos sentidos e dos sujeitos, estando o processo de produção dos sentidos sujeito ao deslize, “[...] havendo sempre um 'outro’ possível que o constitui” (ORLANDI, 2002, p. 79). Como ressalta Mariani (2007, p. 67), "Ora, está em jogo aí tanto a possibilidade de se usar uma palavra ou outra, em função de relações de similitude (sinonímia), quanto a possibilidade de, nesse processo de substituição contextual de uma palavra por outra, chegar-se a um termo bastante distanciado do primeiro, mas que guarda, com esse primeiro termo uma memória de sentido”.

É esse outro possível que constitui os sentidos que emergem das postagens que passam a circular no dispositivo eletrônico a partir de um deslizamento de "Não pense em crise, trabalhe". Temos, nas postagens, vários deslizamentos de sentido, dentre os quais destacamos:

(1) Não pense em crise, trabalhe.

Não pense em crise, lute contra o golpe.

(2) Não pense em crise, trabalhe.

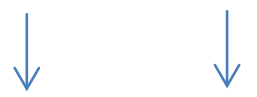

Não pense em golpe, se eleja.

(3) Não pense em crise, trabalhe.<smiles>C1CCCCC1</smiles>

Não pense em crise, me beije. 
A formulação "Não pense em crise, trabalhe" tem seus efeitos metaforizados e deslocados, substituídos e torcidos por um jogo que passa pelo humor, pelo chiste, pelo joke (GADET; PECCHEUX, 2004 [1981]) e pelos vários modos de dizer sobre a crise e o trabalho. Essas substituições contextuais inscrevem os enunciados em outras regiões de sentido imprevisíveis e improváveis para o discurso de Michel Temer. Os enunciados (1) e (2), contraidentificando-se com o discurso de Temer, dizem sobre a questão do impeachment da presidenta Dilma Rousseff ser ou não um golpe. Afirmando tratar-se de um golpe, interpelam os sujeitos para que esses militem e "lutem contra o golpe". No enunciado (2), outro deslocamento. O "trabalhe" é substituído por "eleja”, mostrando como o presidente interino e seus ministros acabaram por chegar ao poder sem o voto direto do cidadão e que interpelam pelo discurso do trabalho e por um dizer da não-crise.

O enunciado (3) joga também com a questão da crise. Podemos dizer que temos nesse outdoor tanto a questão da crise política, quanto à questão da crise amorosa, crise no relacionamento, ambas podendo ser resolvidas com um gesto de amor: "me beije". Rompendo com um discurso do ódio, fortemente em circulação na atualidade, formula um discurso do afeto. Por um funcionamento da memória, rememora-se o também o tão famoso beijo do final da Segunda Guerra Mundial:

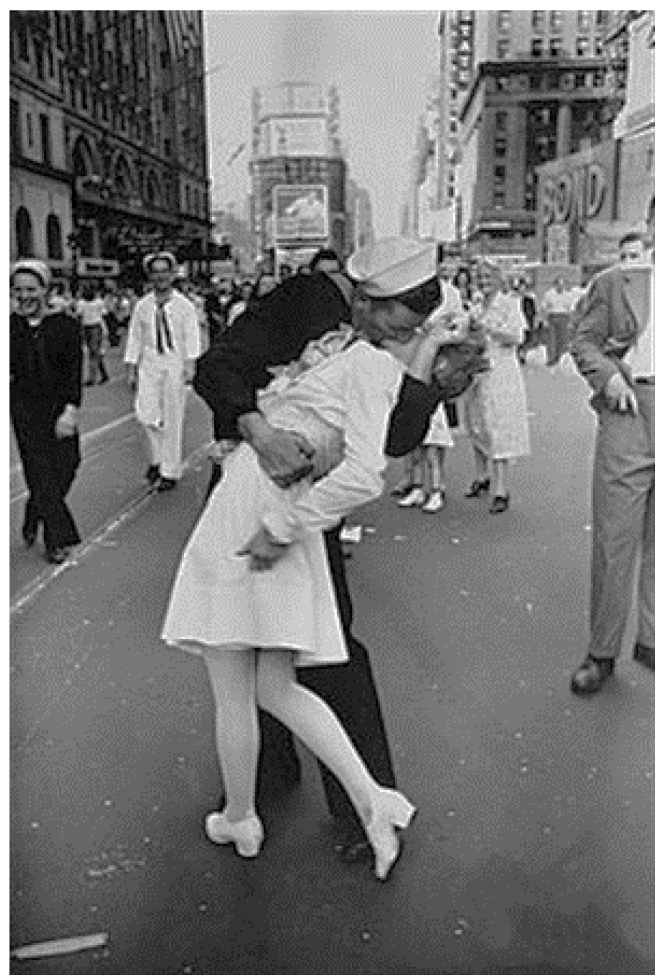

Imagem 6: Beijo final da Segunda Guerra Mundial

Fonte: Eisenstaedt (1945)

Essa fotografia foi tirada por Alfted Eisenstaedt para a Revista Life. Há alguns trabalhos que salientam como esse beijo roubado, que marca o final da Segunda Guerra Mundial, sustenta um discurso da violência de gênero e romantiza um caso de abuso. Isso mostra que, muitas vezes, o gesto de beijar está carregado não de afeto, mas de violência, de silenciamento do outro, de imposição, à força, de diferentes quereres. Transpondo para o campo da política, o enunciado "Não pense em crise, me beije" desloca-se, metaforicamente, para "Não pense em crise, me violente, me abuse". O enunciado inscreve, ao trazer para a memória um exemplo de abuso, a força violenta de um processo de impeachment e de um silenciamento do voto de 54 milhões de brasileiros (seria o beijo calando o desejo de milhões de cidadãos?). Ademais, faz ecoar e reverberar sentidos em torno de uma violência de gênero em que uma sociedade machista violenta não só uma presidenta legitimamente eleita ao fingir beijá-la, mas todas as mulheres brasileiras ao compor os ministérios somente com homens e sem nenhuma presença feminina. 


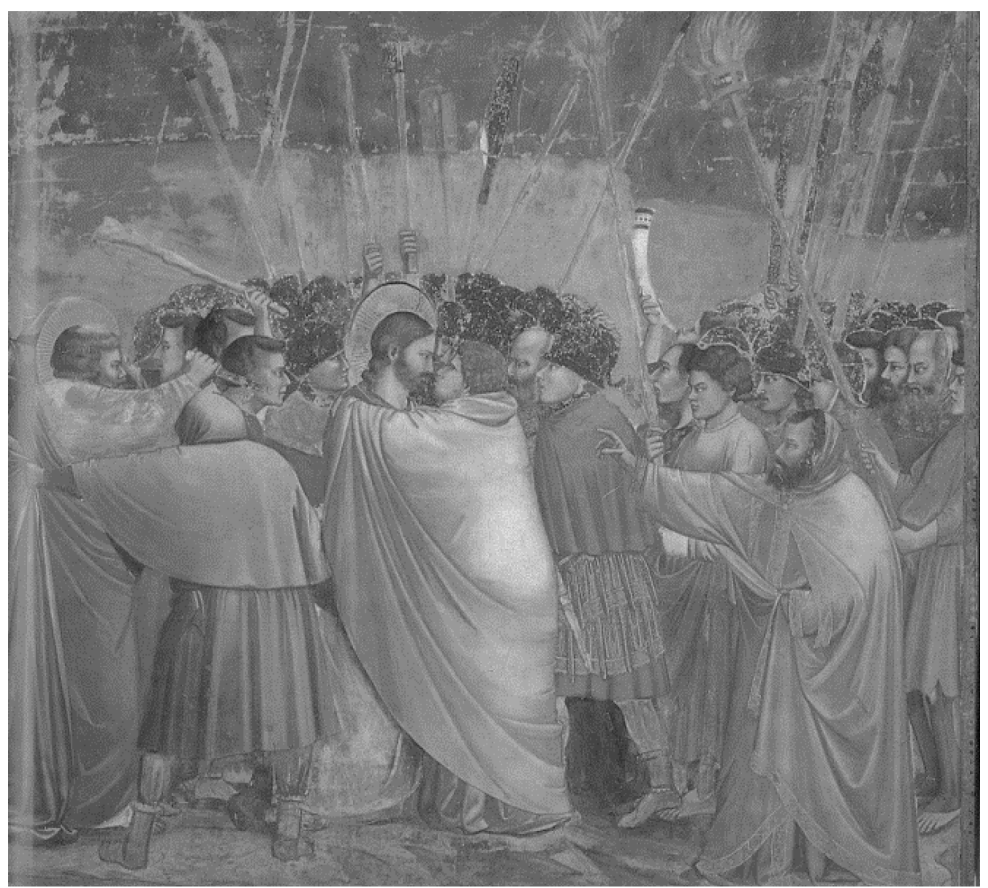

Imagem 7: Beijo de Judas, Quadro de Giotto di Bondone

Fonte: Di Bondone (1304-1306)

Para que os guardas romanos soubessem quem eles tinham que prender, combinaram com Judas, o apóstolo traidor, de dar um beijo em Jesus para saber quem ele era. A partir desse ato, o missionário é preso, torturado e morto em virtude de suas pregações e do auxílio aos mais necessitados. Rememorando esse fato, o enunciado (3), por um efeito metafórico e pelo funcionamento da memória, desloca o "Não pense em crise, me beije" para "Não pense em crise, me traia". Algo que aparece em muitos discursos sobre a traição de Michel Temer ao governo Dilma, o qual o ajudou a se reeleger, mas o qual ele trai para atender não mais aos interesses dos 54 milhões de brasileiros que votaram em Dilma/Temer. Ademais, por meio dessa traição de Temer houve a entrega de Dilma a seus algozes e um início de muitas lutas para que o processo de impeachment não se concretizasse.

Os enunciados (1) e (2) refletem sobre as condições mais atuais do Brasil e a questão política, diferentemente das duas postagens seguintes:

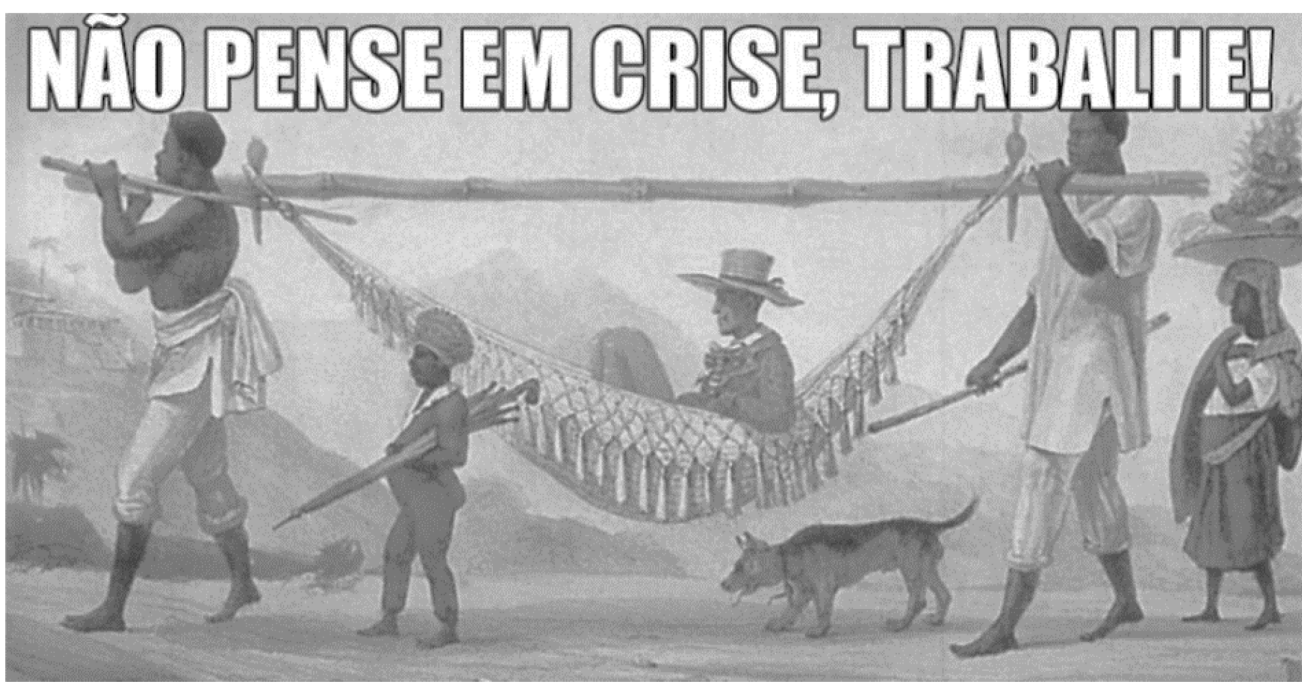

Imagem 8: Não pense em crise...

Fonte: O GOVERNO... (2016) 


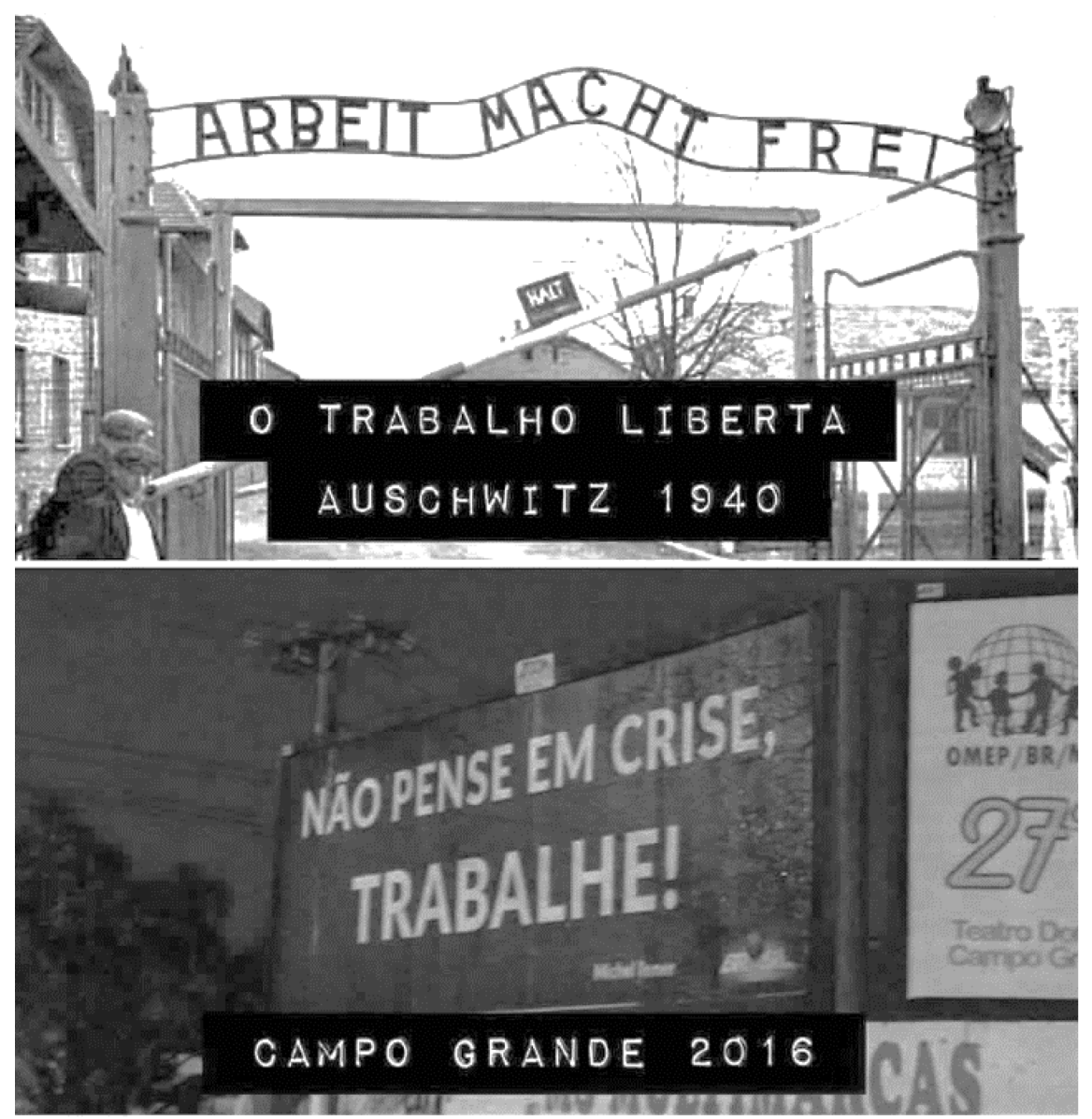

Imagem 8: Não pense em crise...

Fonte: O GOVERNO... (2016)

Nessas duas postagens, não temos a substituição de uma palavra por outra, porém, o efeito metafórico se dá pelo uso das imagens de um quadro de Debret ("O regresso de um proprietário") e do portão do campo de concentração/extermínio de Auschwitz com a inscrição "O trabalho liberta". Ambas as postagens fazem falar o trabalho forçado (escravo) que existiu tanto no Brasil do século XVI ao XIX, como na Polônia, no contexto da Alemanha nazista; em ambos os contextos, também havia certa interdição ao pensar a respeito das condições de vida e trabalho, o que convocava os trabalhadores a apenas fazer uso de sua força física. O trabalho passa a significar rememorando acontecimentos cruéis à humanidade, ambos envolvendo a força e o extermínio. Vistos como propriedades e/ou inimigos, o trabalho nesses espaços não libertava, mas significava sim a morte de negros, ciganos da etnia Romani, homossexuais, alemães de ideologia comunista ou social-democrata, judeus. Nesse extermínio pelo trabalho escravo/forçado, um dizer de hegemonia da sociedade e dos sujeitos. Ao funcionar pela memória a esses dois eventos da história da humanidade (o nazismo e a escravidão), o dizer "Não pense em crise, trabalhe" faz circular um dizer da segregação em que, talvez, só o homem branco, heterossexual, de direta possa "não pensar em crise", pois seus "escravos”, suas "propriedades”, na relação patrão/operário, trabalharão, até o nível da exaustão, para o funcionamento e a sustentação de uma sociedade desigual.

\section{PARA CONCLUIR...}

As postagens que circularam no ciberespaço a partir do discurso de Michel Temer resistem a se filiarem a um discurso de dominação e segregação dos sujeitos, contraidentificando-se com o "Não pense em crise, trabalhe”. Pelo funcionamento metafórico, buscam inscrever os discursos em outras regiões de sentido em que dizeres sobre a dominação, a escravidão, o extermínio e a traição são (re)ditos, deslocados e fazem ranger as relações tão tensas entre o patrão e o proletariado, entre o presidente interino e os cidadãos que não se identificam com esse governo, entre os que têm direito a falar da crise e os que precisam apenas trabalhar. Fazem, ainda, roçar de modo tenso e inesperado os dizeres oficiais e tidos como legitimados, tornando-os matéria de seu próprio desmanche, deslocando-os de acordo com o movimento da história na trama da língua. 


\section{REFERÊNCIAS}

ALTHUSSER, L. Aparelhos ideológicos de Estado: notas sobre os aparelhos ideológicos de Estado. Rio de Janeiro: Edições Graal, 1985. [1970].

BECK, M.; SCHERER, A.E. As modalidades discursivas de funcionamento subjetivo e legado marxista-lenista. Letras, Santa Maria, v. 18, n. 2, p. 169-183, jul./dez. 2008.

CAMPOS, J. Imagem publicada em 2016. Disponível em:<https://twitter.com/juliancampos>. Acesso em 21 mai. 2016.

DI BONDONE, G. Beijo de Judas [Quadro de 1304-1306]. Disponível em: <https://br.pinterest.com/pin/508414245414914847/> Acesso em: 21 mai. 2016.

EISENSTAEDT, A. Imagem publicada em 1945. Disponível em: < https://jornalggn.com.br/noticia/a-polemica-sobre-o-famosobeijo-no-fim-da-segunda-guerra>. Acesso em: 21 mai. 2016.

GADET, F.; PÊCHEUX, M. A língua inatingível: o discurso na história da Linguística. Campinas: Pontes, 2004. [1981].

MANOTELLI. Imagem publicada em 2016. Disponível em: <https://twitter.com/manotelli>. Acesso em 21 mai. 2016.

MARIANI, B. Silêncio e metáfora, algo para se pensar. Revista Trama, Marechal Rondon, v. 3, n. 55, p. 55-71, 2007.

MIATELO, M. Frase de Michel Temer ganha outdoors na Capital. Diário Digital, 13 maio 2016,

Disponível em: <http://www.diariodigital.com.br/politica/frase-de-michel-temer-ganha-outdoors-na-capital/144471/>.Acesso em: 21 mai. 2016.

O GOVERNO Temer. Roda da Cidadania [blog], 15 maio 2016. Disponível em: <https://rodadecidadania.wordpress.com/2016/05/15/633/>. Acesso em: 21 mai. 2016.

OLIVEIRA, E. Imagem publicada em 2016. Disponível em: < https://twitter.com/EdmilsonOlivei8>. Acesso em: 21 mai. 2016.

ORLANDI, E. P. Análise de discurso: princípios e procedimentos. Campinas: Pontes, 2002. . Interpretação. Petrópolis: Vozes, 1996.

PÊCHEUX, M. Análise automática do discurso. In: GABET, F.; HAK, T. Por uma análise automática do discurso: uma introdução à obra de Michel Pêcheux. Campinas: Editora da Unicamp, 1997. [1969]. p.61-161.

Semântica e discurso: uma crítica à afirmação do óbvio. Campinas: Unicamp, 2009. [1988].

; FUCHS, C. A propósito da análise automática do discurso: atualização e perspectiva. In: GABET, F.; HAK, T. Por uma análise automática do discurso: uma introdução à obra de Michel Pêcheux. Campinas: Editora da Unicamp, 1997. p.163-251. 
TVUOL. "Não fale em crise, trabalhe. Queria espalhar essa frase", diz Temer.2016. Disponível em: <https://tvuol.uol.com.br/video/nao-fale-em-crise-trabalhe-queria-espalhar-essa-frase-diz-temer04024E9B3060D8C15326? cmpid=fb-uolnot>. Acesso em: 21 mai. 2016.

TOMAZELA, J. M. Posto que inspirou discurso de Temer vendia combustível adulterado. O Estado de S. Paulo, São Paulo, 16 maio 2016. Disponível em: <http://politica.estadao.com.br/noticias/geral,posto-que-inspirou-discurso-de-temer-vendia-combustiveladulterado,10000051567>. Acesso em: 21 maio 2016.

ZANDWAIS, A. A forma-sujeito do discurso e suas modalidades de subjetivação: um contraponto entre saberes e práticas. In: SEMINÁRIO DE ESTUdOS EM ANÁLISE DO DSICURSO, 1., 2003, Porto Alegre, Rio Grande do Sul. Anais... Porto Alegre: UFRGS, 2003. Disponível em: <http://www.analisedodiscurso.ufrgs.br/anaisdosead/sead1.html>. Acesso em: 21 mai. 2016.

ZOPPI-FONTANA, M. G. Cidadãos modernos: discurso e representação. Campinas: Editora da Unicamp, 1997. 